\title{
Trendelenburg Lithotomy Position During Vaginoscopic Office Hysteroscopy Reduces Pain and Procedure Duration
}

\section{Trendelenburg Litotomi Pozisyonu Vajinoskopik Ofis Histeroskopide Ağrıyı ve İşlem Süresini Azaltır}

\author{
(D) Fatma Ketenci Gencer ${ }^{1}$, (D) Semra Yüksel ${ }^{1}$, (D) Serkan Kumbasar ${ }^{1}$, (D) Bülent Babaoğlu², (D) Berker Kavsi ${ }^{3}$, \\ (1) Süleyman Salman' \\ ${ }^{1}$ University of Health Sciences Hamidiye Medical Faculty, Gaziosmanpaşa Training and Research Hospital, Clinic of Gynecology and \\ Obstetrics, Istanbul, Turkey \\ ${ }^{2}$ Manisa Celal Bayar University Faculty of Medicine, Department of Gynecology and Obstetrics, Manisa, Turkey \\ ${ }^{3}$ Bayrampaşa Kolan Hospital, Clinic of Obstetrics and Gynecology, Istanbul, Turkey
}

\begin{abstract}
Objective: Vaginoscopic office hysteroscopy $(\mathrm{VOH})$ is a gold standard diagnostic method for many uterine disorders. However, it may result in patient discomfort. This study aimed to investigate the effect of the Trendelenburg lithotomy $(T L)$ position, in respect of the level of pain and procedure time during the $\mathrm{VOH}$ for diagnostic purposes.

Methods: This study included 157 patients between the ages of 20 and 65 years, of whom 74 underwent diagnostic VOH with the lithotomy position (group 1) and 83 with the TL position (group 2). Subsequent evaluation that was conducted on both groups included visual analog scale scores of patients, procedure duration, and the attitudinal Likert-type survey of doctors.

Results: A significant difference was found between groups 1 and 2 in pain scores $(p<0.001)$, procedure duration $(p<0.001)$, and attitudinal Likert-type survey of doctors $(p=0.002)$. Group 2 reported lower pain scores than group $1(3.34 \pm 2.37$ and $5.69 \pm 2.33$, respectively). Similarly, the procedure duration in group 2 was significantly reduced $(60.11 \pm 26.3$ and $83.3 \pm 29.5$, respectively). The attitudinal Likert-type survey of doctors also showed significant improvement in group 2 ( $3.48 \pm 0.97$ vs. $3.03 \pm 0.86$, respectively).
\end{abstract}

Conclusion: $\mathrm{VOH}$ with the TL position lowered the pain scores in patients and reduced the procedure duration. The TL position is a good way of increasing the patients' compliance and tolerance. Likewise, it makes the procedure easier for the doctor without any additional price.

Keywords: Vaginoscopic office hysteroscopy, trendelenburg lithotomy position, procedure duration, pain, VAS

\section{öz}

Amaç: Vajinoskopik ofis histeroskopi (VOH) uterin patolojilerin saptanmasında altın standart bir tanı yöntemidir fakat bu işlem hastaya rahatsızlık verebilir. Bu çalışmadaki amacımız tanı amaçlı yapılan $\mathrm{VOH}$ işleminde trendelenburg litotomi pozisyonunun ağrıya ve işlem süresine etkisini araştırmaktır.

Gereç ve Yöntem: Yaşları 20-65 yaş arasında değişen 157 hasta çalışmaya dahil edildi. Hastalardan 74'üne VOH işlemi litotomi pozisyonunda (grup 1) yapılırken, 83'üne trendelenburg litotomi (TL) pozisyonunda (grup 2) yapıldı. Her iki grupta hastalara vizüel analog skalası (VAS) uygulandı, işlem süresi kaydedildi ve doktorlara Likert tipi anket uygulanarak doktorların tutumları değerlendirildi.

Bulgular: Ağrı skorları $(p<0,001)$, işlem süresi $(p<0,001)$ ve doktorların Likert tipi anket sonuçları $(p=0,002)$ açısından grup 1 ve grup 2 arasında anlamlı farklılık bulduk. Grup 2 hastaları, grup 1 hastalarına göre daha düşük ağı skorları bildirdi $(3,34 \pm 2,37,5,69 \pm 2,33)$. Benzer şekilde grup $2^{\prime}$ de işlem sırasında harcanan süre önemli ölçüde azaldı $(60,11 \pm 26,3,83,3 \pm 29,5)$. Doktorların Likert tipi ölçek sonuçlarında da grup 2 'de önemli

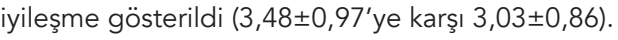

Sonuç: TL pozisyonuda VOH yapılması hastaların ağrı skorlarını düşürdü ve işlem süresini kısalttı. Üstelik hekimler için daha kolay olduğu görüldü. Poliklinik koşullarını VOH açısından optimize etmek için, hastaya TL pozisyonu vermek, hastaların uyumunu ve toleransını artırması bakımından iyi bir yoludur. Aynı şekilde herhangi bir ek maliyeti olmaksızın işlemi doktor için de kolaylaştırmaktadır.

Anahtar Kelimeler: Vajinoskopik ofis histeroskopi, trendelenburg litotomi, işlem süresi, ağrı, VAS

Address for Correspondence: Fatma Ketenci Gencer, University of Health Sciences Hamidiye Medical Faculty, Gaziosmanpaşa Health Application and Research Hospital, Clinic of Gynecology and Obstetrics, Istanbul, Turkey

Phone: +90 5416116469 E-mail: fathma_k@hotmail.com ORCID ID: orcid.org/0000-0002-6076-2563

Cite as: Ketenci Gencer F, Yüksel S, Kumbasar S, Babaoğlu B, Kavsi B, Salman S. Trendelenburg Lithotomy Position during Vaginoscopic Office Hysteroscopy Reduces Pain and Procedure Duration. Med J Bakirkoy 2021;17:298-303

Received: 19.03.2021

Accepted: 19.11.2021 


\section{INTRODUCTION}

Hysteroscopy has been a gold standard for evaluating the uterine cavity for the last four decades (1). "No-touch" vaginoscopic methods are getting more popular than the use of tenaculum or speculum with available equipment $(2,3)$. Studies have shown that pain during the procedure is associated with the diameter of the hysteroscopy, the medium used, vaginal or oral misoprostol usage before the procedure, paracervical blocks, and bladder fullness (4). The most pain is felt during hysteroscopy with the passage through the cervical canal and endometrial biopsy taking (5). The circular cervical diameter is $4-6 \mathrm{~mm}$ in the nulliparous and $7-8 \mathrm{~mm}$ in the multiparous women (1). Hysteroscopy with an outer diameter of $5 \mathrm{~mm}$ and smaller can be used during the procedure. Still, the Bettocchi method allows the passage of the device through the canal without touching the cervical surface with a 30-degree angle optic and reduces the patients' pain $(1,6)$.

Vaginoscopic office hysteroscopy $(\mathrm{VOH})$ is a diagnostic method that is getting more popular in outpatient clinics. Despite its huge contribution to clinical practice, pain during the procedure is an important limiting factor (3). Maneuvers were investigated up to date to reduce pain during the procedure (4). However, research regarding the effectiveness of the position of the patient during the procedure is limited. With the additive effect of gravity, minor upside-down positioning of the patient, who is already in lithotomy position, may fasten and make the procedure easier. Therefore, this study aimed to elucidate the gap in the literature regarding the pain score and procedure duration during $\mathrm{VOH}$ for diagnostic purposes in the Trendelenburg lithotomy (TL) position for the first time. A randomized controlled trial was conducted to compare the pain score and procedure duration between the standard lithotomy position and TL position to gain scientific evidence. Additionally, the convenience for the physician performing the procedure was assessed.

\section{METHODS}

Our prospective randomized controlled study was conducted in University Taksim Traning and Research Hospital between November 2018 and April 2019. The study was approved by the institutional review board of Taksim Traning and Research Hospital (IRB number: 110/2018). Informed consent was signed by all patients before the procedure. The procedure and the possible complications were explained to the participants in detail. $\mathrm{VOH}$ procedure was performed by physicians with at least 3 years of experience. This study performed $\mathrm{VOH}$ solely for diagnostic purposes, thus no biopsy or any other surgical intervention was applied. $\mathrm{VOH}$ was performed in 157 patients aged 20-65 years. Pre-operative complete blood count, coagulation parameters (prothrombin time, activated partial thromboplastin time, and international normalized ratio) for hemorrhagic diathesis, and beta-human chorionic gonadotropin levels to exclude pregnancy were evaluated in all study participants before the treatment. The common indications for $\mathrm{VOH}$ include submucous fibroids, polyps, endometrial adhesion, and Mullerian anomaly. Patients with a history of cervical surgery, fibroids, or masses that narrow the cervical canal, pelvic infection, pregnancy, active bleeding during the procedure, and those with a retroverted uterus in ultrasonography were excluded. Hysteroscopy was performed in the mid-proliferative phase and patients were directed to urinate before the procedure.

The procedure duration was defined as the time that starts from the visualization of the vagina using a vaginoscope with saline, visualization of the cervical canal, endometrial cavity, and ends with both ostia. Neither speculum nor tenaculum was used during the procedure.

Patients were divided into two groups. Group 1 underwent a $\mathrm{VOH}$ procedure in the lithotomy position and group 2 was placed in the TL position, which is an upside-down position with a 30-degree angle (Figure 1).

A power analysis was performed to determine the number of participants, which revealed a minimum patient number of 64 with $80 \%$ power to detect a $30 \%$ difference in cases with an alpha value of 0.05 . This study performed $\mathrm{VOH}$ in 74 patients in the lithotomy position and 83 patients in the TL position. The patient position was randomly selected by the nurse who prepare the patient according to the patient

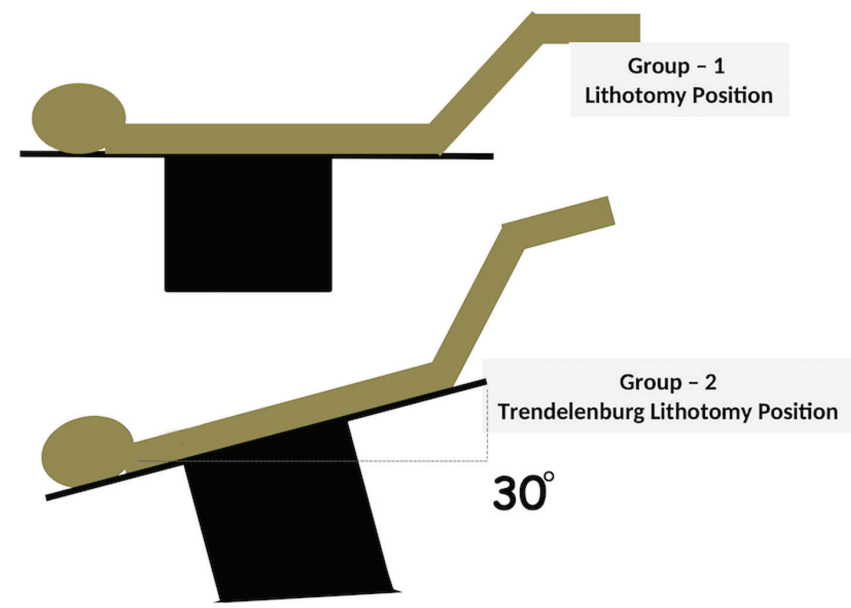

Figure 1. Positions that are preferred during office hysteroscopy. Normal lithotomy position was applied to patients in group 1, whereas $30^{\circ}$ angulated TL position in group 2 
protocol number in the hospital computer program. Patients with the protocol number that ended with an odd number were included in group 1 and the others were included in group 2. All patients were covered with drapes by the nurse before the doctors' arrival to avoid bias, but patients were allowed to watch the procedure from the screen. The procedure was performed using a $4 \mathrm{~mm}$ rigid (Olympus, Hamburg, Germany) hysteroscope with a 30-degree angle optic using a vaginoscopic (no touch) method without analgesia or anesthesia.

The visual analog scale (VAS) was used to evaluate pain levels with 0 that represents pain-free to 10 that described the most painful condition $(6,7)$. Patients were asked to mark the pain expressing point on the VAS immediately after $\mathrm{VOH}$. The pain severity is determined by the value of the point $(\mathrm{cm})$ marked by the participant.

This study evaluated the convenience of the procedure by the physician with a 5-point attitudinal Likert-type survey, which is a psychometric scale that is commonly used to score responses in a questionnaire. The procedure ease or difficulty was categorized as 1 : very easy; 2 : easy; 3: ineffective; 4: difficult; and 5: very difficult, and the performing physician marked the appropriate section for each $\mathrm{VOH}$ procedure in the scale $(8,9)$ (Figure 2).

\section{Statistical Analysis}

Statistical analysis of data was performed with the Statistical Package for the Social Sciences version 24.0 (SPSS Inc., Chicago, USA). The Kolmogorov-Smirnov test was used to evaluate the distribution for normality. Non-parametric variables were compared with the Pearson chi-square test. The Student's t-test or Mann-Whitney $U$ test was used to compare the parametric variables between groups 1 and 2 . Power analysis was performed to determine the minimum sample size to perform the study with G-power (64 patients). $P$-values of $<0.05$ were considered statistically significant.

\section{RESULTS}

This study included 157 patients who applied to our outpatient clinic with different gynecological complaints. Among the participants, 5 patients were excluded from the study since $\mathrm{VOH}$ could not be performed due to vaginal reaction and cervical stenosis in 2 patients in the lithotomy and 3 in the TL position. A total of 74 patients underwent $\mathrm{VOH}$ (group 1) in the lithotomy and 83 in the TL position (group 2). The flow diagram was shown in Figure 1. Positional complications were not reported in any of our patients in both groups.

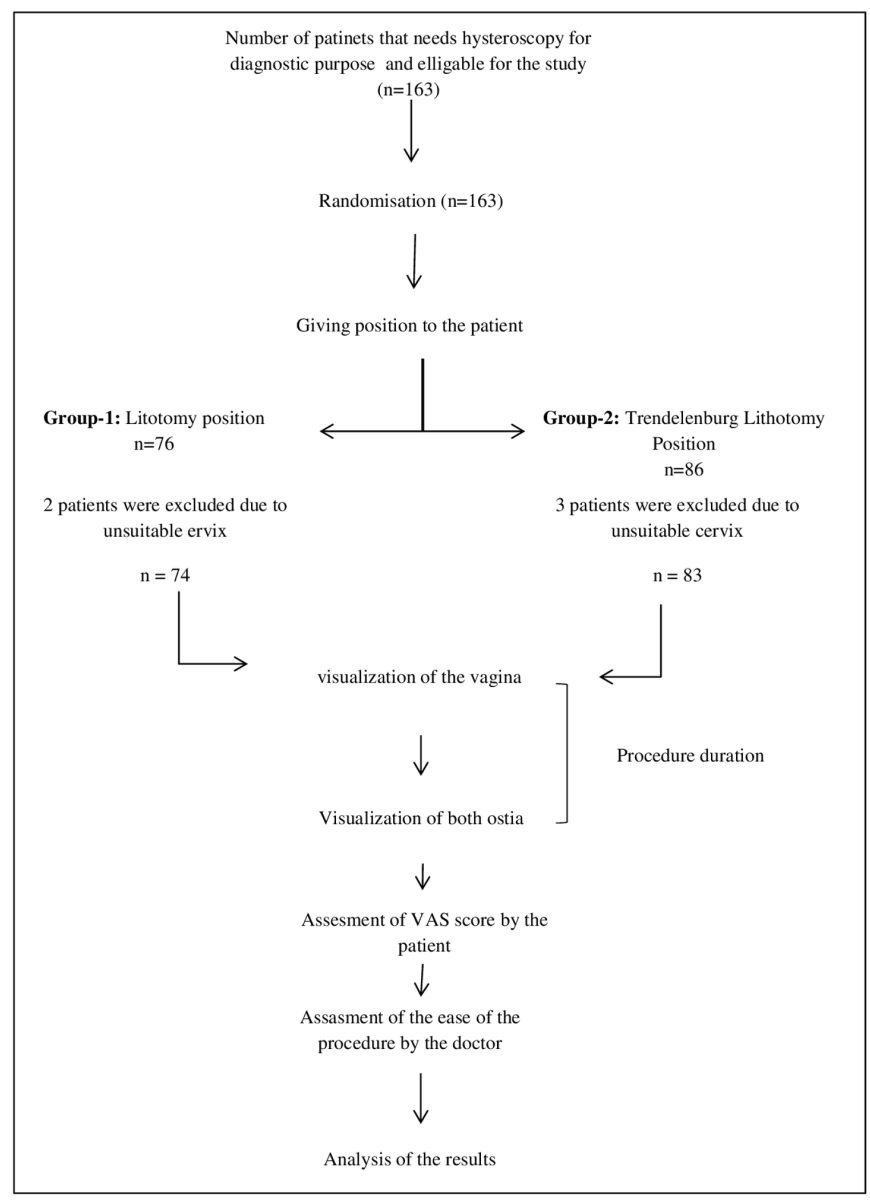

Figure 2. Flow diagram of the study protocol and patient enrollment VAS: Visual analogue scale

The mean age of patients in group 1 was $41 \pm 8.5$ years, whereas in group 2 was $42.3 \pm 10.2$ years. No statistically significant difference was found between the two groups regarding patient age, gravidity, parity, number of abortions, number of curettages, body mass index, reproductive status, and type of delivery (Table 1). Of the total patients that underwent $\mathrm{VOH}, 66$ (42.03\%) had abnormal uterine bleeding, 16 (11.4\%) had infertility, 47 (29.9\%) had an endometrial polyp, 7 (4.4\%) had submucous myoma, and 9 (5.73\%) had other types of indications with no significant difference between the two groups (Table 1). The main findings throughout the whole procedure include endometrial polyp followed by normal cavity and other findings as shown in Table 1.

In group 1, the median VAS scores that were immediately recorded after the procedure was 5 (1-10), the procedure duration was $83.3 \pm 29.5 \mathrm{~s}$, and the attitudinal survey of doctors was $3.48 \pm 0.97$. In group 2, the median VAS score was 3 (0-9), the procedure duration was $60.11 \pm 26.3 \mathrm{~s}$, and the attitudinal survey was $3.03 \pm 0.86$. The pain level, 
procedure duration, and attitudinal survey were statistically different between the groups $(p<0.001, p<0.001$, and $p=0.002$, respectively) (Table 1 ).

\section{DISCUSSION}

Our study revealed lower pain scores and shorter duration of hysteroscopy in TL position than lithotomy position during the procedure $(p<0.001)$. Additionally, the doctor's attitude was evaluated using an attitudinal Likert-type survey during $\mathrm{VOH}$ for the first time and showed that the clinicians were more comfortable when patients were in TL position compared to standard lithotomy position ( $p=0.002)$.
Few studies investigated the maneuvers to reduce pain during diagnostic hysteroscopy. Maneuvers that provide uterine flattening, such as holding the cervix with the tenaculum, filling the bladder, filling the vagina with saline, suprapubic compression, gravity, and Trendelenburg position, facilitate the procedure, and authors compare these in the literature. Török et al. (10) investigated the effect of suprapubic pressure on pain during the procedure and cervical transit time and reported a significant reduction in cervical canal transit time but no effect on pain level. Similar to our study, uterine flattening was related to a shortened duration of the uterine entry. However, any effects were not

Table 1. Baseline characteristics of patients in each group

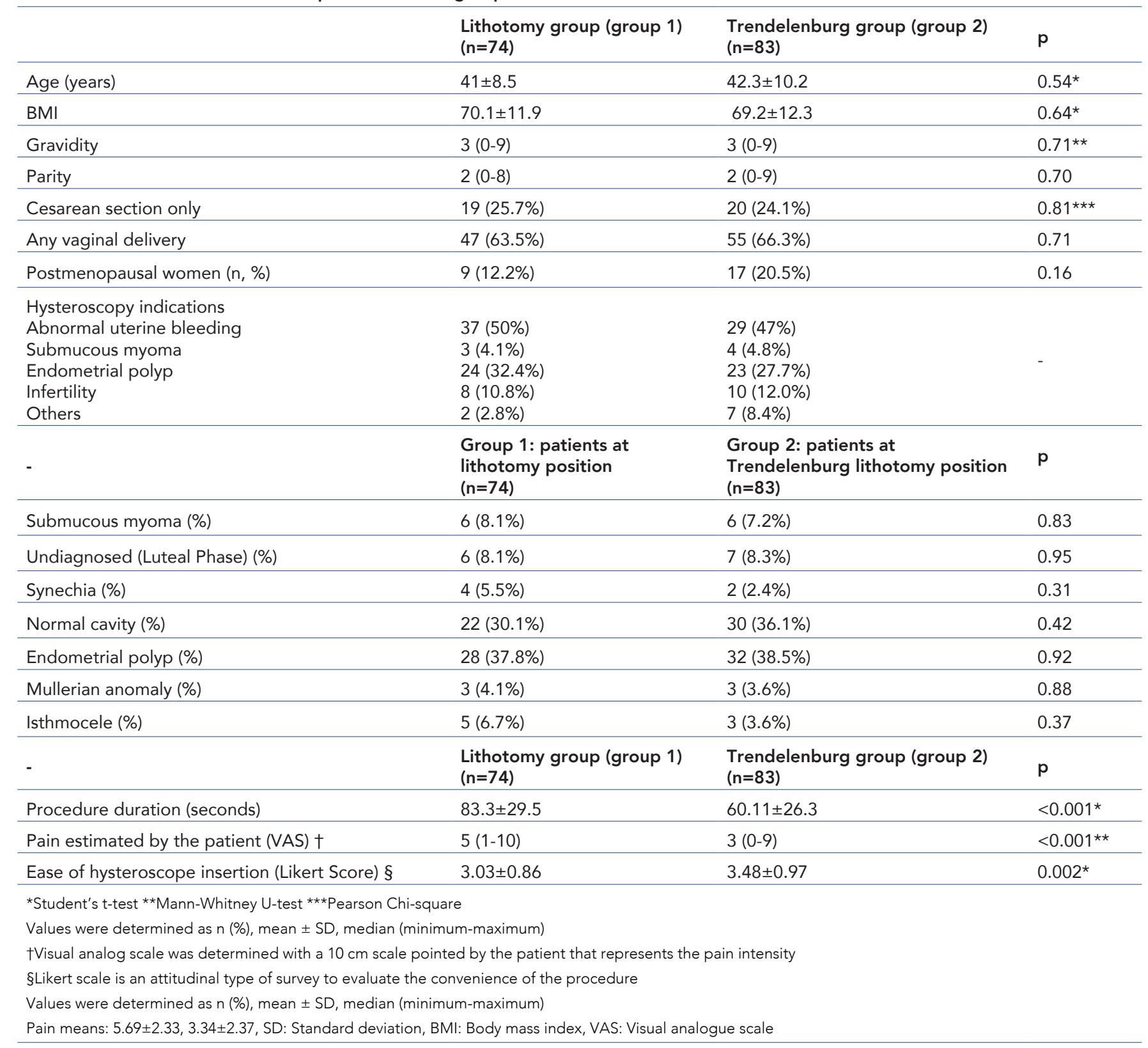


found on pain due to the application pressure and force on both the uterine and cervical canal. Our study revealed a positive effect of uterine flattening on pain reduction due to no further squeezed uterus with suprapubic pressure since we obtained a more flattened uterus by the effect of TL position, as well as the gravity. Additionally, the uterine filling is augmented, and the relatively heavier uterus becomes more flattened. Celik et al. (4) examined the effect of bladder distension and uterine flattening in diagnostic hysteroscopy that was performed using a tenaculum and revealed that bladder distension helps flattened uterus. Patients with bladder distension had lower pain scores and shorter procedure duration than patients with empty bladder during diagnostic hysteroscopy (4).

Our study applied up to a 30-degree Trendelenburg position in the procedures because it had been reported to reduce positional complications (e.g., cardiac output reduction, vital capacity, pulmonary compliance, tidal volume, minute volume decrease, congestive heart failure, pulmonary edema, facial, conjunctival, laryngeal, and tongue swelling, etc.). Additionally, advantages were also reported, such as decreased bleeding risk, facilitated surgical viewing distance, difficult trachea regurgitation, etc. $(1,11)$.

The vaginal filling was effectively provided when the TL position was given to patients with an empty bladder. Thus, quick vaginal filling enables the medium to reach the optimum pressure force, which will dilate the cervical canal more quickly and effectively, leading to a more physiological dilatation before the cervical visualization than the lithotomy position. The medium does not overflow from the vagina by the effect of gravity until the vagina is filled, thus facilitating the full filling of the uterine cavity. With the effect of gravity on the relatively heavier uterus and TL position, uterine flattening is achieved. Therefore, easy entrance through a flat uterus improved the pain score of patients and shortened the duration of the procedure. Additionally, similar results were obtained in both studies because both were performed based on providing uterine flattening with simple techniques. In our method, the rapid vaginal filling with the medium by gravity facilitated image acquisition. We believe that when the patient can witness the vaginoscopic monitoring of cervical ostium, the tolerance and compliance increase, together with uterine flattening, which resulted in reduced pain scores and decreased procedure duration in the TL group. Contrarily, Fouda et al. (12) designed a study in a group of menopausal women and compared the effect of $400 \mathrm{mg}$ vaginal misoprostol administration $12 \mathrm{~h}$ before the procedure and bladder straightening by instructing the patients to drink $1 \mathrm{I}$ of water $2 \mathrm{~h}$ before the procedure to achieve bladder filling. They found that vaginal misoprostol administration was superior to bladder straightening for harboring pain management (12). The main determinant point in this study is that the menopausal woman has an extra narrow cervix due to hormonal status; therefore, cervical ripening due to misoprostol facilitated the entrance. Bladder straightening seemed insufficient because the cervix was more straightened but still narrow. Our study did not exclude the menopausal woman in both groups, thus the mean and the median of our main outcomes were still comparable even with the negative effect of patients who are menopausal. Main outcomes may improve in a group of non-menopausal women.

Many medical studies have used the Likert scale to achieve more scientific and accurate conclusions, particularly in subjective assessments. The Likert scale was used by Nandhini et al. (13) in a patient group administered with $200 \mathrm{mcg}$ vaginal misoprostol $3 \mathrm{~h}$ before vaginoscopic hysteroscopy and a non-administered patient group and revealed that the procedure got easy and the complication was less in the misoprostol group. Nada et al. (14) applied $400 \mathrm{mcg}$ of oral and vaginal misoprostol to patients 12 $h$ before the operative hysteroscopy. Surgeons were evaluated on how easy the cervical dilatation was using a Likert scale and revealed that oral or vaginal administration did not affect the convenience of the surgeon. Likert scale setting and scoring technique in our study revealed that the doctors found the procedure easier when patients were in the TL position than the lithotomy position $(p=0.002)$.

The comprehensive study by Kabli and Tulandi (15) revealed no difference for pain score when using a mixture of lidocaine and saline as a distending medium compared to only the saline used to group. Our study revealed lower visual pain scores in the TL group $(p<0.001)$ without any analgesic agent administration, which can be useful if added to our method since the response of flattened uterus to analgesics during the $\mathrm{VOH}$ procedure was undetermined.

Karakuş et al. (16) compared the effectiveness of local anesthesia methods for analgesia in diagnostic hysteroscopy and demonstrated that patients with cervical spray application had less pain during tenaculum insertion compared to placebo. Additionally, intrauterine topical anesthesia reduced pain during and after the procedure (16). Tenaculum was not used in our vaginoscopic procedure. Thus, pain due to the tenaculum was ignored in both groups. Hence, we just assessed the pain while passing through the canal and visualizing the cavity. Pain scores and procedure duration might be further reduced with local or intrauterine topical anesthesia in the TL group. 
De Angelis et al. (17) revealed that the application of a subcutaneous electrical nerve stimulation device in-office hysteroscopy was associated with lower pain. Maybe, a combination of this non-invasive method with ours improves pain scores and shortens the procedure duration.

\section{Study Limitations}

Study limitations include the absence of a subgroup composed of menopausal women since the number of menopausal participants in each group is limited, thus their results are not comparable.

\section{CONCLUSION}

In light of these findings, hysteroscopy is a procedure that can be applied even in outpatient clinics. Many different applications and technical procedures have been tried to achieve optimal standards. This study revealed that performing $\mathrm{VOH}$ in $\mathrm{TL}$ position provided shorter procedure duration and lower pain scores. Additionally, the clinicians found the TL position more comfortable than the lithotomy position. Placing patients in a TL position is simple, cheap, and worth it since pain is still a limiting factor for $\mathrm{VOH}$ despite new feasible equipment. More studies that focus on combinations of our technique with others in the literature are needed to achieve a better and more qualified environment both for the patient and the operator during office hysteroscopy.

\section{Ethics}

Ethics Committee Approval: Our prospective randomized controlled study was conducted in University Taksim Traning and Research Hospital between November 2018 and April 2019. The study was approved by the institutional review board of Taksim Traning and Research Hospital (IRB number: 110/2018).

Informed Consent: Written consent was obtained from all patients before attending the study.

\section{Authorship Contributions}

Surgical and Medical Practices: F.K.G., B.B., Concept: F.K.G., Design: F.K.G., B.K., Data Collection or Processing: F.K.G., B.B., S.Y., S.K., Analysis or Interpretation: S.Y., S.K., Literature Search: B.K., S.S., Writing: F.K.G., B.K.,

Conflict of Interest: No conflict of interest was declared by the authors.

Financial Disclosure: The authors declared that this study received no financial support.

\section{REFERENCES}

1. Bettocchi S, Nappi L, Ceci O, Selvaggi L. What does 'diagnostic hysteroscopy' mean today? The role of the new techniques. Curr Opin Obstet Gynecol 2003;15:303-8.

2. Neves AR, Mairos J, Martino PD. How the Location of Intracavitary Lesions Influences Pain during Office Hysteroscopy. J Minim Invasive Gynecol 2019;26:1334-9.

3. Tagliaferri V, Ricciardi L, Ricciardi R, Pinto LR, Lanzone A, Scambia $G$, et al. Carbon dioxide in office diagnostic hysteroscopy: An open question. A multicenter randomized trial on 1982 procedures. Eur J Obstet Gynecol Reprod Biol 2019;235:97-101.

4. Celik C, Tasdemir N, Abali R, Bastu E, Akbaba E, Yucel SH. The effect of uterine straightening by bladder distention before outpatient hysteroscopy: a randomised clinical trial. Eur J Obstet Gynecol Reprod Biol 2014;180:89-92.

5. De Angelis C, Santoro G, Re ME, Nofroni I. Office hysteroscopy and compliance: mini-hysteroscopy versus traditional hysteroscopy in a randomized trial. Hum Reprod 2003;18:2441-5.

6. Ekin M, Yaşar Y, Akgöl S. Comparison of Vaginoscopic No Touch Method with The Traditional Method of Outpatient Hysteroscopy. Med J Bakirkoy 2009;5:63-6.

7. Price DD, McGrath PA, Rafii A, Buckingham B. The validation of visual analogue scales as ratio scale measures for chronic and experimental pain. Pain 1983;17:45-56.

8. Şahin DB, Gülleroğlu HD. Examination of the psychometric properties of scale developed through item analysis techniques that are used to select items for Likert-type. Asian Journal of Instruction 2013;1:18-28.

9. Lınkert R. A Technique fort he Measurement of Attitudes. Archives of Psychology 1932;22:140-55.

10. Török P, Herman T, Lőrincz J, Molnár S, Lampé R, Póka R. Suprapubic pressure facilitates the procedure of office hysteroscopy: A randomized controlled trial. Obstet Gynaecol Res 2019;45:640-4.

11. Min JH, Lee SE, Lee HS, Chae YK, Lee YK, Kang Y, et al. The correlation between the Trendelenburg position and the stroke volume variation. Korean J Anesthesiol 2014;67:378-83.

12. Fouda UM, Elshaer HS, Elsetohy KA, Youssef MA. Misoprostol versus uterine straightening by bladder distension for pain relief in postmenopausal patients undergoing diagnostic office hysteroscopy: a randomised controlled non-inferiority trial. Eur J Obstet Gynecol Reprod Biol 2016;203:326-30.

13. Nandhini B, Maurya DK, Keepanasseril A, Kubera NS. Effect of cervical priming with misoprostol on cervical entry in women undergoing vaginoscopic hysteroscopy for evaluation of abnormal uterine bleeding: a randomized controlled trial. Arch Gynecol Obstet 2018;298:133-7.

14. Nada AM, Elzayat AR, Awad MH, Metwally AA, Taher AM, Ogila Al, et al. Cervical Priming by Vaginal or Oral Misoprostol Before Operative Hysteroscopy: A Double-Blind, Randomized Controlled Trial. J Minim Invasive Gynecol 2016;23:1107-12.

15. Kabli N, Tulandi T. A randomized trial of outpatient hysteroscopy with and without intrauterine anesthesia. J Minim Invasive Gynecol 2008;15:308-10.

16. Karakuş R, Namazov A, Ayas S, Polat M, Arınkan SA, Angın AD, et al. Efficacy of local anesthesia for office hysteroscopy. Zeynep Kamil Med J 2014;45:136-41

17. De Angelis C, Perrone G, Santoro G, Nofroni I,Zichella L. Suppression of pelvic pain during hysteroscopy with a transcutaneous electrical nerve stimulation device. Fertil Steril 2003;79:1422-7. 